\title{
Pemodelan Inversi Data Geolistrik untuk Menentukan Struktur Perlapisan Bawah Permukaan Daerah Panasbumi Mataloko
}

\author{
Eko Minarto* \\ Laboratorium Geofisika \\ Jurusan Fisika, FMIPA, Institut Teknologi Sepuluh Nopember \\ Kampus ITS Sukolilo, Surabaya 60111
}

\begin{abstract}
Intisari
Metode geolistrik (tahanan jenis) merupakan metode geofisika yang sangat popular dan sering digunakan baik dalam survey geologi maupun eksplorasi. Hal ini disebabkan karena metode geolistrik sangat bagus untuk mengetahui kondisi atau struktur geologi bawah permukaan berdasarkan variasi tahanan jenis batuannya, terutama untuk daerah yang mempunyai kontras tahanan jenis yang cukup jelas terhadap sekitarnya, misalnya untuk keperluan eksplorasi air tanah, panasbumi (geothermal). Penyelidikan panasbumi daerah Mataloko dengan menggunakan metode tahanan listrik konfigurasi Schlumberger, menunjukkan bahwa daerah tersebut mempunyai potensi struktur panasbumi yang ditunjukkan oleh nilai tahanan jenis yang relatif kecil. Hasil pemodelan inversi dengan menggunakan program IPI2WIN diperoleh model perlapisan bumi yang cukup bagus dengan eror dibawah 5\% untuk setiap titik sounding. True section kedua lintasan menunjukkan bahwa terdapat lapisan yang bersifat konduktif dengan resistivitas $<5 \Omega \mathrm{m}$ pada kedalaman sekitar $800 \mathrm{~m}-1000 \mathrm{~m}$ yang diperkirakan sebagai lapisan penudung dan lapisan dibawahnya $(>1000 \mathrm{~m})$ yang bersifat agak resistif $(10 \Omega \mathrm{m}$ $100 \Omega \mathrm{m}$ ) yang diperkirakan sebagai reservoir dari sumber panasbumi daerah Mataloko.
\end{abstract}

KATA KUNCI: geolistrik, tahanan jenis, Schlumberger, true section

\section{PENDAHULUAN}

Sumber daya alam panasbumi dewasa ini menjadi salah satu sumber energi alternatif yang banyak dikembangkan di banyak negara di dunia. Hal ini mengingat semakin sedikitnya cadangan minyak bumi yang tersedia yang selama ini menjadi sumber energi primadona. Tidak terkecuali Indonesia berusaha mengembangkan sumber energi panasbumi sebagai sumber energi alternatif. Fakta menunjukkan bahwa Indonesia merupakan daerah yang berpotensi akan sumber daya alam, termasuk sumber daya panasbumi. Diperkirakan Indonesia mempunyai potensi sumber daya sekitar 20.000 MW sumber panasbumi. Sampai saat ini baru sekitar 3,04\% dari sumber daya yang ada atau kurang dari 1000 MW yang sudah dieksplorasi [1], sehingga perlu dilakukan penyelidikan lebih lanjut untuk pemanfaatan sumber daya panasbumi yang cukup potensial tersebut.

Metode geolistrik merupakan salah satu metode geofisika yang sangat popular dan sering digunakan baik dalam survey geologi maupun eksplorasi. Hal ini disebabkan karena metode geolistrik sangat bagus untuk mengetahui kondisi atau struktur geologi bawah permukaan berdasarkan variasi tahanan jenis batuannya. Terutama untuk daerah yang mempunyai kontras tahanan jenis yang cukup jelas terhadap sekitarnya, seperti untuk keperluan eksplorasi panasbumi.

*E-MAIL: oke_aji@plasa.com
TABEL I: Potensi sumber daya panasbumi Indonesia (2000)

\begin{tabular}{lc}
\hline \hline Daerah & Daya geothermal (MW) \\
\hline Kamojang & 140 \\
Salak & 330 \\
Darajat & 125 \\
Dieng & 60 \\
Sibayak & 2 \\
Lahendong & 2.5 \\
Wayang Windu & 110 \\
\hline Total & 769.5 \\
\hline \hline
\end{tabular}

Metode geolistrik dapat digunakan untuk mengidentifikasi struktur bawah permukaan dalam penyelidikan panasbumi. Hal ini dapat ditunjukkan dengan penampang harga tahanan jenis yang mencerminkan karakteristik fisik atau struktur bawah permukaan. Kondisi ideal geologi yang memenuhi persyaratan daerah panasbumi yang dapat menghasilkan uap panas adalah adanya sumber panas, adanya batuan reservoir dengan porositas dan permeabilitas cukup tinggi berisi fluida panas (ada pengisian kembali air dingin melalui rekahan atau sesar), serta adanya batuan penutup (cap rock) yang dapat menahan pelepasan panas [2].

\section{TINJAUAN DAERAH PENYELIDIKAN}

Sumber panasbumi Mataloko mempunyai posisi geografis antara $08^{\circ} 48^{\prime} 30^{\prime \prime}-08^{\circ} 53^{\prime} 30^{\prime \prime}$ Lintang Selatan dan $121^{\circ} 00^{\prime}$ 


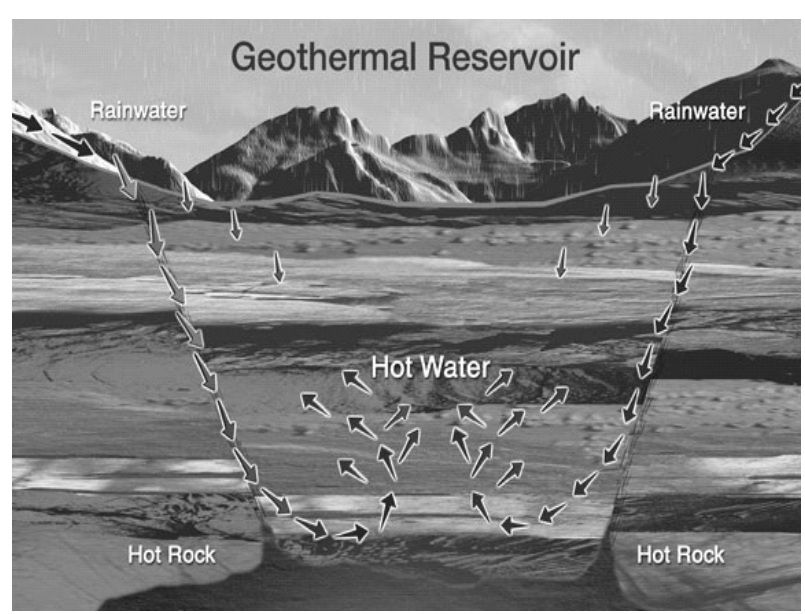

Gambar 1: Skema sumber panasbumi

- $121^{\circ} 05^{\prime}$ Bujur Timur atau tepatnya terletak diperbatasan antara Kecamatan Golewa dan Kecamatan Aimere, Kabupaten Ngada, Flores, Nusa Tenggara Timur.

Daerah panasbumi Mataloko mempunyai kondisi geologi yang cukup ideal dan memenuhi persyaratan daerah panasbumi yang cukup potensial untuk dapat menghasilkan uap panas. Hal ini didukung selain dengan adanya sumber panas, adanya batuan reservoir dengan porositas dan permeabilitas cukup tinggi, serta adanya batuan penutup yang dapat menahan pelepasan panas, juga didukung adanya beberapa sesar yang berfungsi pada pengisian kembali air sebagai reservoir. Beberapa struktur sesar yang ada didaerah panasbumi Mataloko antara lain: sesar Bopa terletak di bagian selatan daerah penyelidikan (disekitar kampung Bopa), sesar Tudaluda terletak di bagian barat daya daerah penyelidikan (di sekitar kampung Tedaluda), sesar Were terletak di bagian tenggara daerah penyelidikan (di sekitar kampung Were), serta sesar Waeluja terletak di bagian selatan daerah penyelidikan (di sekitar kampung Mataloko) [3].

\section{KONFIGURASI TAHANAN JENIS SCHLUMBERGER}

Survey geolistrik pada umumnya bertujuan untuk mengetahui kondisi atau struktur geologi bawah permukaan berdasarkan variasi tahanan jenis batuannya [4]. Struktur geologi yang dapat dideteksi dengan metode ini terutama yang mempunyai kontras tahanan jenis yang cukup jelas terhadap sekitarnya, misalnya untuk keperluan eksplorasi air tanah, mineral, panasbumi. Prinsip pelaksanaan survey tahanan jenis adalah menginjeksikan arus listrik melalui elektroda arus dan mengukur responnya (tegangan) pada elektroda potensial dalam suatu susunan tertentu [5].

Berdasarkan tujuan dan cara pengubahan jarak elektroda, survey geofisika dibagi menjadi dua cara: mapping dan sounding. Mapping dimaksudkan untuk mengetahui variasi horizontal atau lateral tahanan jenis batuan pada kedalaman tertentu. Jarak antar elektroda dibuat tetap sesuai dengan kedalaman daya penetrasi yang diinginkan, selanjutnya selu- ruh susunan elektroda dipindahkan menurut suatu lintasan tertentu. Sedangkan sounding dimaksudkan untuk mengetahui variasi tahanan jenis batuan terhadap kedalaman (secara vertikal). Jarak antar elektroda diperbesar dalam suatu arah bentangan pada suatu titik tertentu [6].

Konfigurasi metode geolistrik Schlumberger bertujuan untuk mengidentifikasi diskontinuitas lateral (anomali konduktif lokal). Arus diinjeksikan melalui elektroda $\mathrm{AB}$, dan pengukuran beda potensial dilakukan pada elektroda $\mathrm{MN}$ [7], dengan jarak elektroda arus $(\mathrm{AB})$ jauh lebih besar dari jarak elektroda tegangan (MN), seperti ditunjukkan Gambar 2.

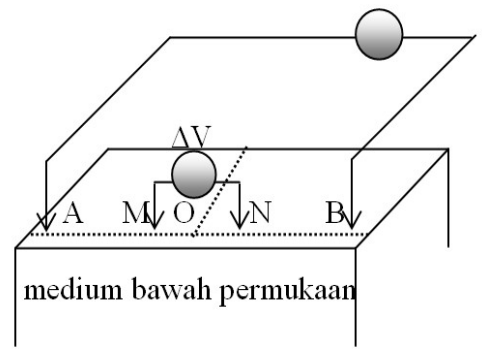

Gambar 2: Skema metode tahanan jenis konfigurasi Schlumberger.

Struktur resistivitas bumi adalah variasi harga resistivitas terhadap kedalaman dari permukaan tanah, dapat dinyatakan:

$$
\rho_{i}=f\left(z_{i}\right)
$$

Tahanan jenis dan kedalaman tiap lapisan dapat diturunkan dari persamaan:

$$
V_{r}=\frac{\rho_{i} I}{2 \pi} \int_{0}^{\propto}\left[1+2 \theta_{1}(\lambda)\right] J_{\circ}(\lambda r) d \lambda
$$

dengan $\mathbf{J}_{\circ}=$ Fungsi Bessel orde ke nol, $\theta_{1}(\lambda)=$ Fungsi Kernel $\left(\rho_{i}, d_{i}\right)$.

Secara umum harga tahanan jenis semu dinyatakan oleh hubungan sebagai berikut:

$$
\rho_{a}=K \frac{\Delta V}{I}
$$

dengan $\mathrm{K}$ adalah faktor geometri, $\Delta V$ merupakan beda potensial, dan I berupa arus listrik.

Untuk bumi homogen berlaku:

$$
\rho=\left(\frac{\Delta V}{I}\right) 2 \pi\left(\frac{A B}{2}\right)\left[\frac{\left(\frac{A B}{2}\right)^{2}-\left(\frac{M N}{2}\right)^{2}}{4\left(\frac{A B}{2}\right)\left(\frac{M N}{2}\right)}\right]
$$

dengan faktor geometri K,

$$
K=2 \pi\left(\frac{A B}{2}\right)\left[\frac{\left(\frac{A B}{2}\right)^{2}-\left(\frac{M N}{2}\right)^{2}}{4\left(\frac{A B}{2}\right)\left(\frac{M N}{2}\right)}\right]
$$




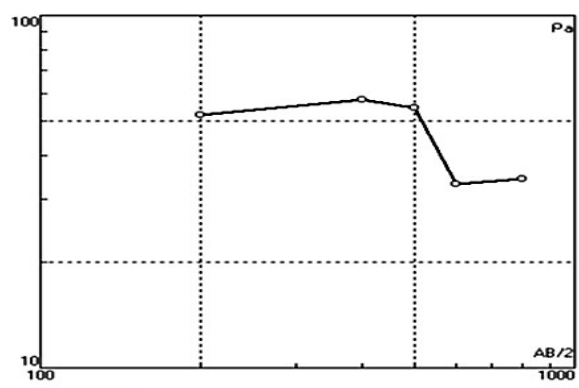

Gambar 3: Kurva pengukuran lapangan.

\begin{tabular}{c}
\hline \hline Permukaan bumi \\
\hline$\uparrow \mathrm{d}_{1}, \rho_{1}$ \\
\hline$\uparrow \mathrm{d}_{2}, \rho_{2}$ \\
\hline$\uparrow \mathrm{d}_{3}, \rho_{3}$ \\
\hline$\uparrow \mathrm{d}_{4}, \rho_{4}$
\end{tabular}

Gambar 4: Model perlapisan bumi.

Pengukuran dilapangan menggunakan konfigurasi Schlumberger, jarak elektroda arus (AB) jauh lebih besar dari jarak elektroda tegangan $(\mathrm{MN})$. Data yang diperoleh dari pengukuran dilapangan adalah besarnya arus dan beda potensial. Jarak $\mathrm{AB} / 2=200,400,500,600$, dan $800 \mathrm{~m}$, sedang jarak $\mathrm{MN} / 2=80 \mathrm{~m}$. Sehingga dapat dihitung harga tahanan jenis semu berdasarkan Pers.(4). Terdapat dua buah lintasan E dan $\mathrm{K}$ dengan masing-masing terdiri dari 10 titik amat.

\section{ANALISIS}

Pengukuran geolistrik konfigurasi Schlumberger daerah panasbumi Mataloko dilakukan pada 20 titik sounding yang terbagi dalam 2 lintasan, masing-masing sebanyak 10 titik sounding pada lintasan E dan lintasan K. Hasil pemodelan inversi dengan menggunakan program IPI2WIN, diperoleh hasil model perlapisan bumi yang cukup bagus dengan eror rata-rata untuk setiap titik sounding dibawah 5\%, (data perhitungan yang hampir mendekati harga observasi) baik untuk

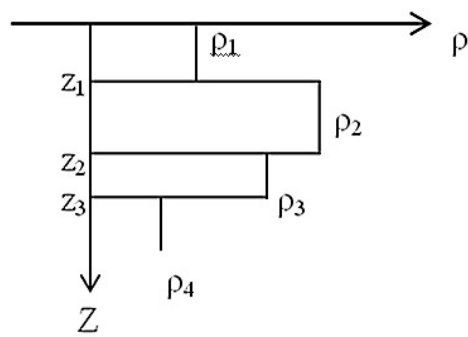

Gambar 5: Struktur resistivitas bumi.

\begin{tabular}{|c|c|c|c|c|}
\hline $\mathbf{N}$ & p & h & d & Alt \\
\hline 1 & \multirow{5}{*}{$\begin{array}{l}58.3 \\
3076 \\
217 \\
2.96 \\
30.5\end{array}$} & \multirow{5}{*}{$\begin{array}{l}49.3 \\
7.05 \\
155 \\
754\end{array}$} & \multirow{5}{*}{$\begin{array}{l}49.3 \\
56.3 \\
211 \\
965\end{array}$} & \multirow{5}{*}{$\begin{array}{c}-49.3 \\
-56.35 \\
-211.4 \\
-965\end{array}$} \\
\hline 2 & & & & \\
\hline 3 & & & & \\
\hline 4 & & & & \\
\hline 5 & & & & \\
\hline & & & & \\
\hline $\mathbf{N}$ & $\mathbf{p}$ & h & d & Alt \\
\hline 1 & 369 & 8.34 & 8.34 & -8.338 \\
\hline 2 & 68.6 & 62.5 & 70.9 & -70.88 \\
\hline 3 & 660 & 71.9 & 143 & -142.8 \\
\hline 4 & 4.73 & 735 & 878 & -877.6 \\
\hline 5 & 58.6 & & & \\
\hline & & & & \\
\hline
\end{tabular}

(a)

\begin{tabular}{|c|c|c|c|c|}
\hline $\mathbf{N}$ & p & h & d & Alt \\
\hline 1 & 79.1 & 34.4 & 34.4 & -34.4 \\
\hline 2 & 37.7 & 1.88 & 36.3 & -36.28 \\
\hline 3 & 331 & 177 & 213 & -213.3 \\
\hline 4 & 2.39 & 774 & 987 & -987 \\
\hline 5 & 45 & & & \\
\hline
\end{tabular}

\begin{tabular}{|c|c|c|c|c|}
\hline $\mathbf{N}$ & $\mathbf{p}$ & h & d & Alt \\
\hline 1 & 17.9 & 49.9 & 49.9 & -49.9 \\
\hline 2 & 162 & 3.88 & 53.8 & -53.78 \\
\hline 3 & 250 & 82.3 & 136 & -136 \\
\hline 4 & 2.96 & 691 & 827 & -827.5 \\
\hline 5 & 24.9 & & & \\
\hline
\end{tabular}

(b)

Gambar 6: Harga resistivitas dan kedalaman tiap lapisan beberapa titik sounding untuk lintasan (a). E, (b). K.

lintasan E maupun lintasan K (Gambar 7 dan Gambar 8).

Dari hasil true section kedua lintasan memberikan penafsiran bahwa pada kedua lintasan terdapat lapisan konduktif dengan resistivitas $<5 \Omega \mathrm{m}$ pada kedalaman sekitar $800 \mathrm{~m}$ - $1000 \mathrm{~m}$ yang diperkirakan sebagai lapisan penudung dan lapisan di bawahnya yang bersifat agak resistif $(10 \Omega \mathrm{m}-100$ $\Omega \mathrm{m})$ yang diperkirakan sebagai reservoir dari sumber panasbumi daerah Mataloko (Gambar 9).

\section{SIMPULAN}

1. Metode geolistrik dengan konfigurasi Schlumberger dapat digunakan untuk mengidentifikasi diskontinuitas lateral (anomali konduktif lokal) bawah permukaan sumber panasbumi.

2. Pemodelan inversi dengan menggunakan program IPI2WIN memberikan hasil model perlapisan bumi yang cukup bagus. Hal ini dibuktikan dengan didapatkan eror yang cukup kecil untuk setiap titik sounding pada kedua lintasan, yaitu dibawah $5 \%$ (data perhi tungan yang hampir berimpit dengan data observasi).

3. Secara umum hasil pengukuran menunjukkan bahwa pada kedua lintasan terdapat lapisan yang bersifat konduktif dengan resistivitas $<5 \Omega$ m pada kedalaman sekitar 800 m - 1000 m yang diperkirakan sebagai lapisan penudung dan lapisan dibawahnya $(>1000 \mathrm{~m})$ yang bersifat agak resistif (10 $\Omega \mathrm{m}-100 \Omega \mathrm{m})$ yang diperkirakan sebagai reservoir dari sumber panasbumi daerah Mataloko. 

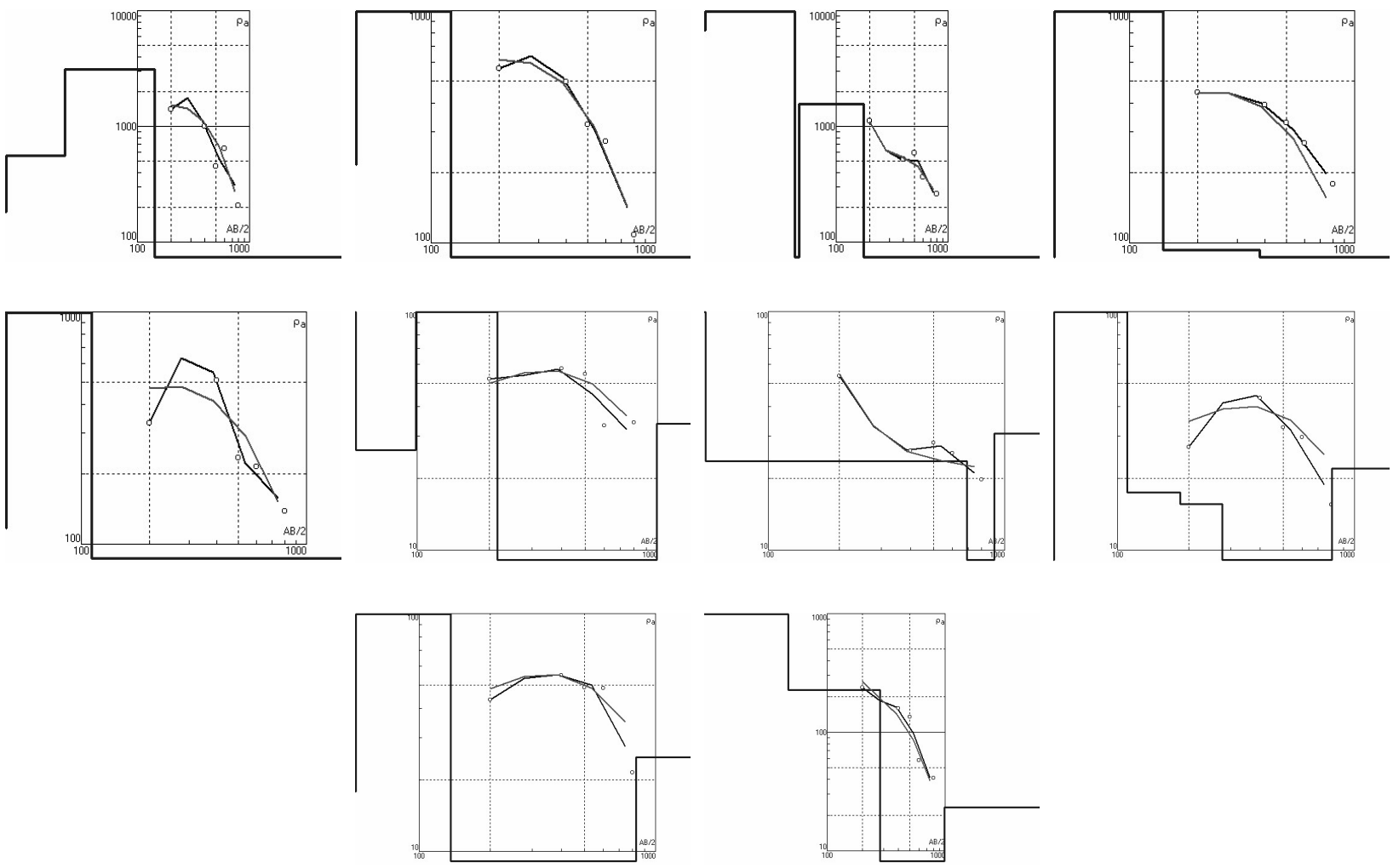

Gambar 7: Model perlapisan bumi untuk masing-masing titik sounding untuk lintasan E.
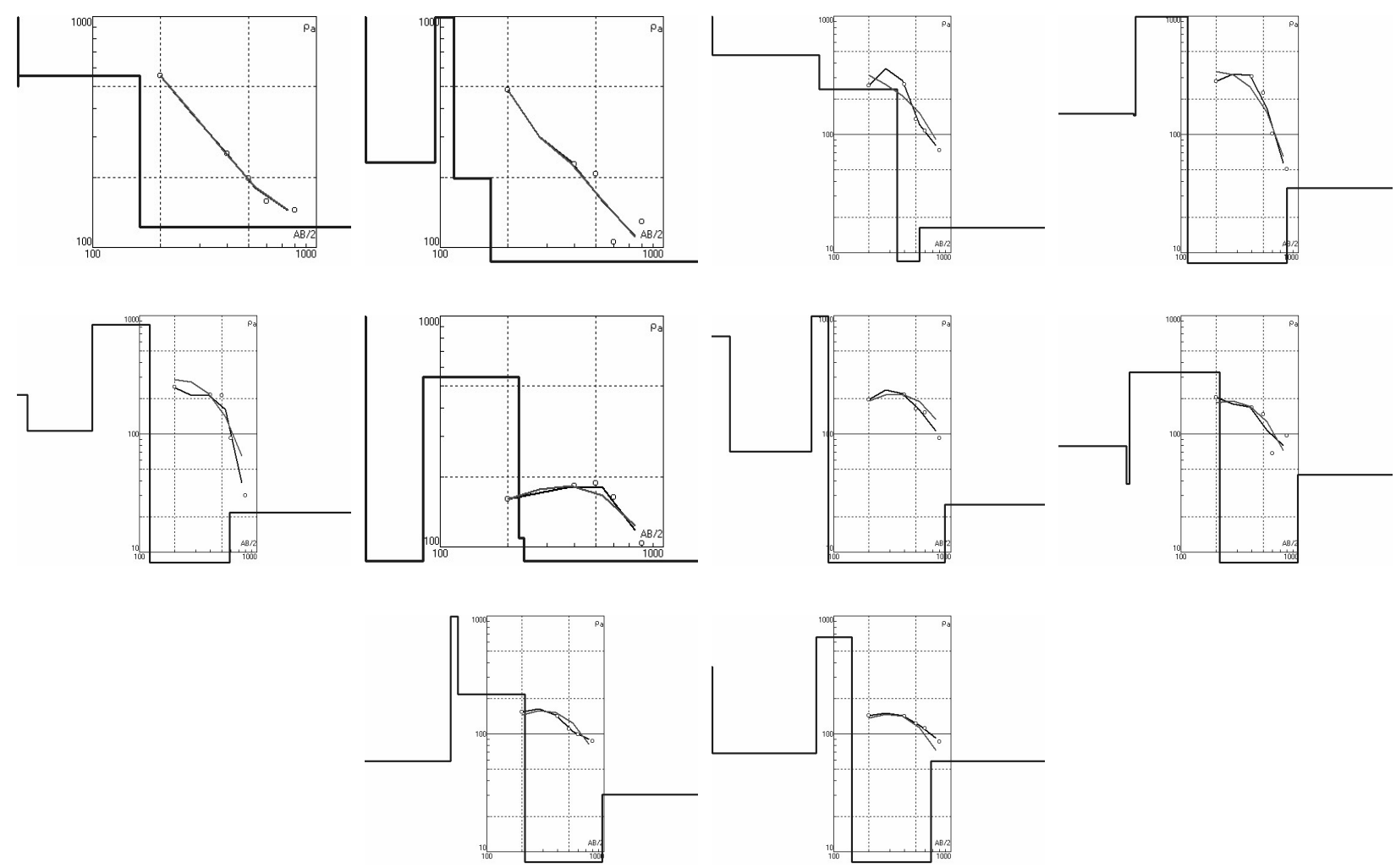

Gambar 8: Model perlapisan bumi untuk masing-masing titik sounding untuk lintasan K. 


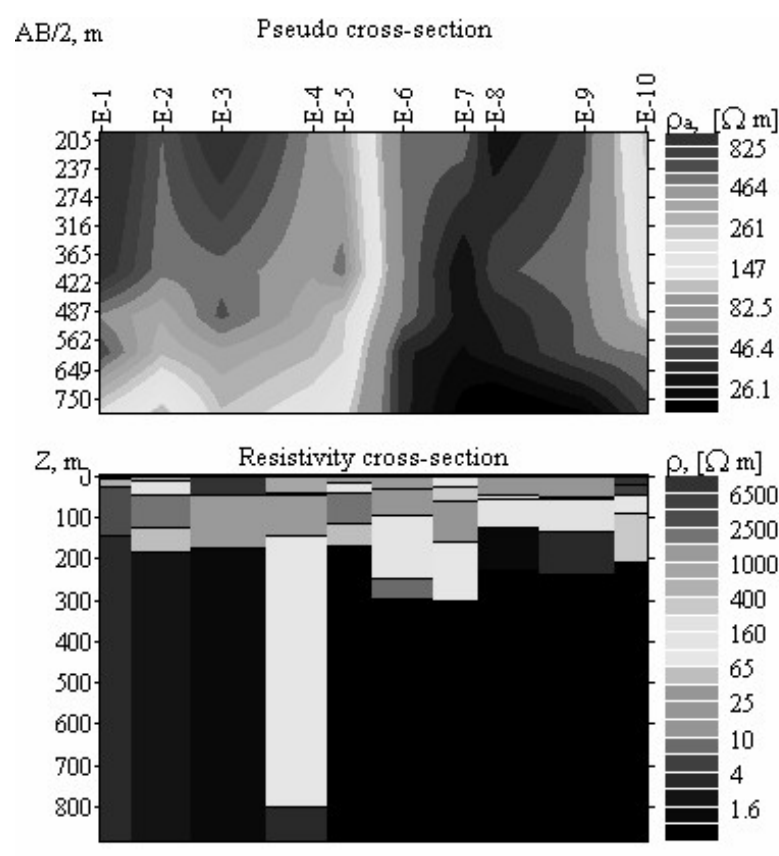

(a)

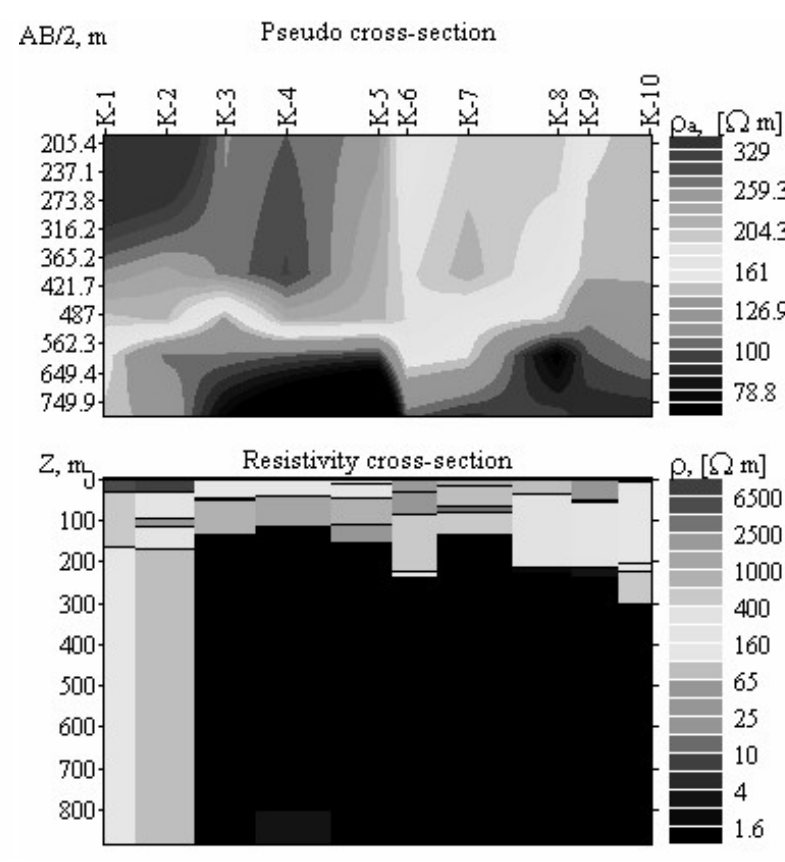

(b)

Gambar 9: Penampang resistivitas semu (Pseudo-Section) dan resistivitas sebenarnya (true section) untuk lintasan (a). E, (b). K.

[1] http://geothermal.marine.org, Geothermal Education Office, (2000).

[2] D.S. Parasnis, Principles of Applied Geophysics, second Edition, (Chapman and Hall, New York, 1972).

[3] Fredy Nanlohi, dkk., Geologi Daerah Panasbumi Mataloko, Kabupaten Ngada - Flores Nusa Tenggara Timur, Laporan Direktorat Vulkanologi, 1997.

[4] H. Grandis, Penerapan Metode Gaya Berat dan Tahanan Jenis Dalam Eksplorasi Pendahuluan Daerah Prospek Panasbumi, Tu- gas Akhir Jurusan GM-ITB, 1986.

[5] M. P. Hochstein, Introduction to Geothermal Prospecting (Geothermal Institut, University of Auckland, 1982).

[6] O. Koefoed, Geosounding Principles: Resistivity Sounding Measurement (Elsevier, 1979).

[7] W. M. Telford, L. P. Geldart, and R. E. Sheriff, Applied Geophysics, Second Edition (Cambridge and Hall, New York, 1990). 